\title{
EVALUATION OF CLONIDINE FOR ATTENUATION OF HAEMODYNAMIC RESPONSES DURING LARYNGOSCOPY AND INTUBATION
}

\author{
Parthsarthi Prasad ${ }^{1}$
}

${ }_{1}^{1}$ Assistant Professor, Department of Anaesthesiology, GMC, Ambikapur, Surguja, Chhattisgarh, India.

ABSTRACT
BACKGROUND
The commonest and most discussed side effects of laryngoscopy and endotracheal intubation are acute rise in blood pressure,
tachycardia and transient arrhythmias. Clonidine, an alpha-2 adrenoreceptor agonist has been shown to attenuate the
cardiovascular response during laryngoscopy and intubation by various workers.
The aim of the present study was to evaluate effect of clonidine on attenuation of haemodynamic responses during
laryngoscopy and intubation.

\section{MATERIALS AND METHODS}

This study was a prospective, double-blinded, randomised controlled trial conducted on 60 patients of both sexes within the age of 18-60 years, ASA grade I and II physical status, MPS-I or II admitted for elective abdominal surgeries under general anaesthesia. Patients were randomly divided into two groups containing 30 patients in each group, received normal saline or clonidine $3 \mu \mathrm{g} / \mathrm{kg}$ 15 minutes before induction of anaesthesia. Pulse rate, blood pressure, oxygen saturation and ECG changes were recorded from baseline to 10 minutes after laryngoscopy and intubation at fixed time intervals.

\section{RESULTS}

Both groups were demographically similar and comparable at baseline. The pulse rates and blood pressures were increased in both groups upto 1 minute after laryngoscopy and intubation, then decreased progressively and similar to baseline in 10 minutes. Increase in pulse rates and blood pressures were found much more in Group I than Group II. It was seen that clonidine prevents rise in pulse rates and blood pressures in Group II and leads to early normalisation of haemodynamic changes. There was no noticeable change on ECG and oxygen saturation in both groups during the study period. The side effects and complications of clonidine like bradycardia and hypotension were not observed in any patient during the study period.

\section{CONCLUSION}

In conclusion, Clonidine is beneficial in attenuating the haemodynamic responses to laryngoscopy and intubation. So, clonidine is a useful pre-medicant for routine use.

\section{KEY WORDS}

Clonidine, Laryngoscopy and Intubation, Haemodynamic Responses, General Anaesthesia.

HOW TO CITE THIS ARTICLE: Prasad P. Evaluation of clonidine for attenuation of haemodynamic responses during laryngoscopy and intubation. J. Evolution Med. Dent. Sci. 2018;7(37):4109-4113, DOI: 10.14260/jemds/2018/919

\section{BACKGROUND}

Intubation of trachea is the most secure and life-saving intervention that is performed to establish and maintain a patent airway for administering anaesthesia. The commonest and most discussed side effects of laryngoscopy and endotracheal intubation are acute rise in blood pressure, tachycardia and transient arrhythmias. The effects of laryngoscopy and tracheal intubation on the cardiovascular system were noted by Reid and Brace, ${ }^{1}$ who concluded that cardiac reflexes originate in the trachea, larynx, bronchi or lungs. King et $\mathrm{al}^{2}$ first described the influence of airway manipulation on the heart rate and blood pressure. These responses are thought to be initiated by lifting the base of tongue and epiglottis by the laryngoscope blade and tracheal stimulation while intubating, which leads to activation of

'Financial or Other Competing Interest': None.

Submission 29-07-2018, Peer Review 24-08-2018,

Acceptance 31-08-2018, Published 10-09-2018.

Corresponding Author:

Parthsarthi Prasad,

Near Jaiswal Bhawan,

Bouripara, Ambikapur,

Surguja-497001, Chhattisgarh, India.

E-mail: parthsarthiprasad@yahoo.in

DOI: $10.14260 /$ jemds $/ 2018 / 919$ sympathetic nervous system by vagal and glossopharyngeal afferent and manifested by rise of catecholamine levels. Prys Roberts et $\mathrm{al}^{3}$ concluded that hypertensive patients are prone to much greater changes in blood pressure than normotensive patients.

Attempts to attenuate these haemodynamic alterations have been made with various techniques as well as drugs by different workers all over the world. Clonidine, an alpha-2 adrenoreceptor agonist has been shown to attenuate the cardiovascular response during laryngoscopy and intubation by various workers. Batra et $\mathrm{al}^{4}$ and Nishikawa et $\mathrm{al}^{5}$ studied the effect of oral clonidine and found it was very effective in attenuation of haemodynamic responses during laryngoscopy and intubation. Carbine UA et $\mathrm{al}^{6}$ and Leslie et $\mathrm{al}^{7}$ used clonidine intravenously and found that it was effective in attenuation of the pressure response to intubation. F. Marinangeli and C. Cocco et al 8 demonstrated that $3 \mu \mathrm{g} / \mathrm{kg}$ BW clonidine is an appropriate dosage for effective and safe pre-medication.

The aim of the present study was to evaluate the effects of clonidine on attenuation of haemodynamic responses during laryngoscopy and intubation. 


\section{MATERIALS AND METHODS}

This study was a prospective, double-blind, randomised controlled trial conducted in Patna Medical College and Hospital, Patna on 60 patients of both sexes within the age of 18-60 years, ASA grade I and II physical status, MPS-I or II admitted for elective abdominal surgeries under general anaesthesia. Patients taking antihypertensive drugs and patients with suspected difficult airways were excluded from the study.

Patients were randomly divided into two groups containing 30 patients in each group who received normal saline or clonidine $3 \mu \mathrm{g} / \mathrm{kg}, 15$ minutes before induction of anaesthesia. Randomisation was done using computergenerated random number table. The double-blinding procedure was followed, in which the person administering the drug and the patients both were unaware as to which group the patient belonged to. The anaesthesiologist prepared drugs and coded them. The prepared drugs were given to resident, who was unaware of the contents, to be administered to the patients. At the end of the study, results were analysed and then decoding was done.

On the day of surgery patients were connected with multipara monitor and baseline pulse rate, blood pressure, ECG and oxygen saturation were recorded. A Ringer's lactate solution was started with a large bore IV cannula. Then the study drug was given according to group of the patients. Preoxygenation with $100 \%$ oxygen was done for three minutes, before then induction was done by Inj. Propofol $1-2 \mathrm{mg} / \mathrm{kg}$ body weight followed by Inj. Rocuronium $0.6 \mathrm{mg} / \mathrm{kg}$ body weight for relaxation. Intermittent positive pressure ventilation was carried out for 1.5 minutes. Then laryngoscopy was performed, and intubation was done with adequate size cuffed endotracheal tube. Pulse rate, blood pressure, oxygen saturation and ECG changes were recorded at laryngoscopy and intubation and 1, 5 and 10 minutes after laryngoscopy and intubation. Inhalational anaesthetic agent halothane was added to anaesthetic mixture after study period. After completion of surgery, neuromuscular block was reversed with neostigmine and glycopyrrolate combination. After adequate recovery, patients were extubated and shifted to post-operative ward.

\section{Sample Size Determination}

The sample size was estimated using the changes in mean HR at 5 minutes after laryngoscopy and intubation in both groups. We assumed that a difference of 10 BPM in mean HR would be clinically meaningful with expected standard deviation of 11.2 based on a preliminary study and at $95 \%$ confidence limit and $90 \%$ power. Sample size of 27 was obtained in each group. With $10 \%$ non-response sample size of $27+2.7,30$ patients were included in the study in both groups.

\section{Statistical Analysis}

Statistical analysis was done by SPSS version 15 for analysing the collected data. Results on continuous measurements are presented as mean \pm SD and results on categorical measurements are presented in number. Student's ' $t$ ' test was used for comparison of continuous data between two groups. Proportions were analysed by the use of the Chi-square test or Fisher's test. Results were considered statistically significant if $p<0.05$, highly significant if $p<0.001$ and not significant if $\mathrm{p}>0.05$.

\section{RESULTS}

The results and observations of the cases in the present study are shown in the following tables and figures and explained thereby-

\section{[A] Demographic Variables}

\begin{tabular}{|c|c|c|}
\hline Characteristics & Group-I & Group-II \\
\hline No. of patients & 30 & 30 \\
\hline Mean age (yrs.) \pm SD & $32.13 \pm 9.99$ & $33.4 \pm 11.49$ \\
\hline Males & 9 & 9 \\
\hline Females & 21 & 21 \\
\hline Mean body wt. (kgs) \pm SD & $58.1 \pm 6.08$ & $59.07 \pm 6.74$ \\
\hline ASA-I & 30 & 30 \\
\hline ASA-II & 0 & 0 \\
\hline MPS-I & 24 & 25 \\
\hline MPS-II & 6 & 5 \\
\hline Table 1. Demographic Data of the patients Under Study \\
\hline
\end{tabular}

Both groups were demographically similar and comparable. The differences in their means and standard deviations were statistically insignificant $(p>0.05)$.

\section{[B] HAEMODYNAMIC VARIABLES 1. Pulse Rate}

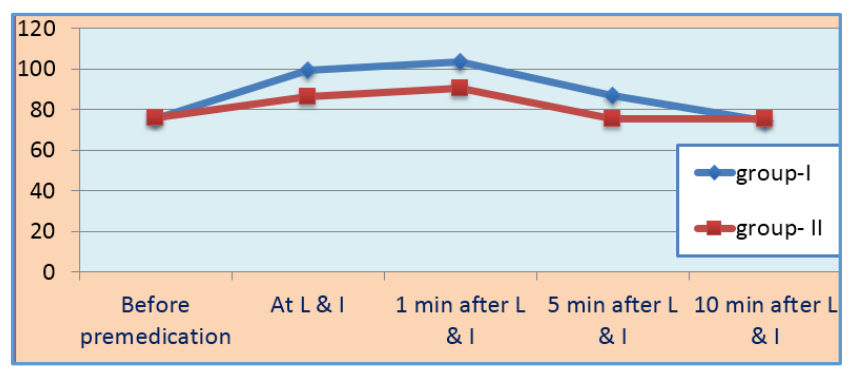

Figure 1. Variation of Mean Pulse Rate at Different Time Intervals

\begin{tabular}{|c|c|c|c|}
\hline Time Interval & Group-I & Group-II & P-value \\
\hline Before premedication & $75.6 \pm 6.69$ & $75.9 \pm 5.02$ & $>0.05$ \\
\hline $\begin{array}{c}\text { At laryngoscopy and } \\
\text { intubation }\end{array}$ & $99.3 \pm 4.43$ & $86.57 \pm 3.33$ & $<0.0001$ \\
\hline 1 min after L and I & $103.4 \pm 4.69$ & $90.6 \pm 3.46$ & $<0.0001$ \\
\hline 5 min after L and I & $86.7 \pm 3.88$ & $75.3 \pm 3.82$ & $<0.0001$ \\
\hline 10 min after L and I & $74.33 \pm 6.25$ & $75.33 \pm 2.96$ & $>0.05$ \\
\hline
\end{tabular}

Table 2. Statistical Significance of Mean Pulse Rates \pm SD (bpm) at Different Time Intervals in the Groups

At the baseline (before premedication) mean pulse rate values were not found to be statistically significantly different ( $p>0.05)$ between both groups. The mean pulse rates of patients in both groups were increased from laryngoscopy and intubation, peak at 1 minute after laryngoscopy and intubation and gradual decline upto 10 minutes after laryngoscopy and intubation. Differences were found to be significant upto 5 minutes and were not significant 10 minutes after laryngoscopy and intubation. 


\section{Systolic Blood Pressure}

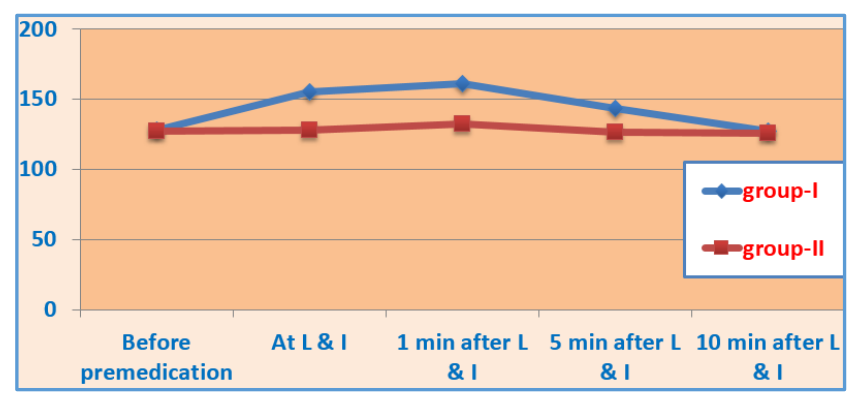

Figure 2. Variation of Mean Systolic Blood Pressure at Different Time Intervals

\begin{tabular}{|c|c|c|c|}
\hline Time Interval & Group-I & Group-II & P-value \\
\hline Before premedication & $127.7 \pm 7.41$ & $127.03 \pm 6.54$ & $>0.05$ \\
\hline $\begin{array}{c}\text { At laryngoscopy and } \\
\text { intubation }\end{array}$ & $155.5 \pm 6.89$ & $127.77 \pm 4.58$ & $<0.0001$ \\
\hline 1 min after L and I & $161.3 \pm 9.51$ & $132.4 \pm 5.04$ & $<0.0001$ \\
\hline 5 mins after L and I & $143.63 \pm 6.92$ & $126.2 \pm 4.25$ & $<0.0001$ \\
\hline 10 mins after L and I & $127.2 \pm 4.46$ & $125.56 \pm 3.82$ & $>0.05$ \\
\hline \multicolumn{4}{|c|}{ Table 3 } \\
\hline
\end{tabular}

Table 3. Statistical significance of mean systolic blood pressure \pm SD (mmHg) at different time intervals in the groups.

At the baseline (Before premedication), mean systolic blood pressure values were not found to be statistically significantly different $(p>0.05)$ between both groups. The mean systolic blood pressures of patients in both groups were increased from laryngoscopy and intubation, peak at 1 minute after laryngoscopy and intubation and gradual decline upto 10 minutes after laryngoscopy and intubation. Differences were found significant upto 5 minutes and were not significant 10 minutes after laryngoscopy and intubation.

\section{Diastolic Blood Pressure}

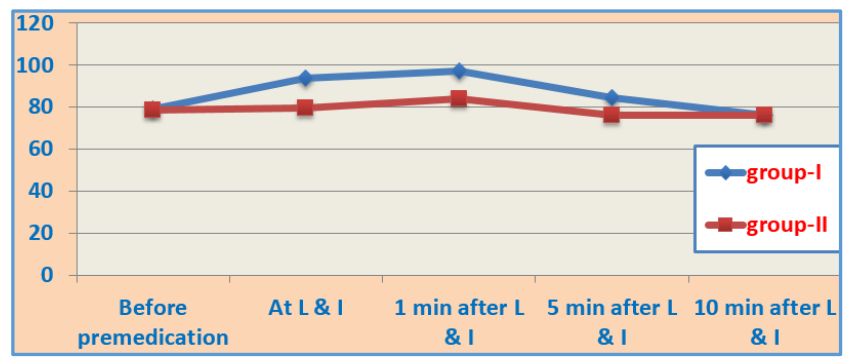

Figure 3. Variation of Mean Diastolic Blood Pressure at Different Time Intervals

\begin{tabular}{|c|c|c|c|}
\hline Time Interval & Group-I & Group-II & P-value \\
\hline Before premedication & $78.93 \pm 4.93$ & $78.77 \pm 4.17$ & $>0.05$ \\
\hline $\begin{array}{c}\text { At laryngoscopy and } \\
\text { intubation }\end{array}$ & $93.67 \pm 4.98$ & $79.73 \pm 2.45$ & $<0.0001$ \\
\hline 1 min after L and I & $97.33 \pm 4.47$ & $83.77 \pm 3.46$ & $<0.0001$ \\
\hline 5 mins after L and I & $84.57 \pm 2.52$ & $76.33 \pm 2.86$ & $<0.0001$ \\
\hline 10 mins after L and I & $76.23 \pm 4.13$ & $76.03 \pm 3.41$ & $>0.05$ \\
\hline \multicolumn{4}{|c|}{ Table 4 } \\
\hline
\end{tabular}

Table 4. Statistical significance of mean diastolic blood pressure \pm SD ( $\mathrm{mmHg}$ ) at different time intervals in the groups.
At the baseline (before premedication), mean diastolic blood pressure values were not found to be statistically significantly different $(\mathrm{p}>0.05)$ between both groups. The mean systolic blood pressures of patients in both groups were increased from laryngoscopy and intubation, peak at 1 minute after laryngoscopy and intubation and gradual decline upto 10 minutes after laryngoscopy and intubation. Differences were found to be significant upto 5 minutes and were not significant 10 minutes after laryngoscopy and intubation.

\section{ECG Changes}

There was no noticeable ECG change in any patient during the study period in all three groups.

\section{Oxygen Saturation}

The oxygen saturation of the patients was within the range of $97 \%$ to $100 \%$ in all three groups during the study period. The variations in oxygen saturation were not significant.

\section{DISCUSSION}

The most discussed side effects of laryngoscopy and endotracheal intubation are acute rise in blood pressure, tachycardia and transient arrhythmias which have been confirmed and reported by various authors like King et al, 2 Prys Roberts et $\mathrm{al}^{3}$ and Marion Devault ${ }^{9}$ etc. These responses are thought to be initiated by lifting the base of tongue and epiglottis by the laryngoscope blade and tracheal stimulation while intubating leads to activation of sympathetic nervous system by vagal and glossopharyngeal afferent and manifested by rise of catecholamine levels. Attempts to attenuate these haemodynamic alterations have been made with various techniques as well as drugs by different workers all over the world like King et $\mathrm{al}^{2}$ Stoelting, ${ }^{10}$ Parnass et al ${ }^{11}$ etc.

Clonidine is an alpha-2 adrenoreceptor agonist. It decreases central sympathetic outflow and used as antihypertensive agent. It has been shown to attenuate the cardiovascular responses during laryngoscopy and intubation by various workers like Batra et al, ${ }^{4}$ Carbine UA et al, ${ }^{6}$ Leslie et al7 etc. They found encouraging results with cardiovascular response during intubation in hypertensive patients.

This study was conducted on 60 patients of both sexes within the age of 18 - 60 years, ASA grade I and II physical status, MPS-I or II admitted for elective abdominal surgeries under general anaesthesia. Patients were randomly divided into two groups containing 30 patients in each group who received normal saline or clonidine $3 \mu \mathrm{g} / \mathrm{kg}, 15$ minutes before induction of anaesthesia. The dose of intravenous clonidine was also $3 \mu \mathrm{g} / \mathrm{kg}$, which corroborated with study by Zalunardo et al ${ }^{12}$ and $\mathrm{F}$ Marinangeli et al who have used the same dose.

Both groups were demographically similar and comparable at baseline. The differences in their means and standard deviations were statistically insignificant ( $p>0.05$ ).

The mean pulse rates before premedication in Group I was $75.6 \pm 6.69$ and Group II was $75.9 \pm 5.02$ beats per minute. The mean systolic blood pressures before premedication in Group I was $127.7 \pm 7.41$ and Group II was $127.03 \pm 6.54 \mathrm{mmHg}$. The mean diastolic blood pressures before premedication in Group I was $78.93 \pm 4.93$ and Group II was $78.77 \pm 4.17 \mathrm{mmHg}$. Comparison between both groups 
with respect to pulse rates, systolic blood pressures and diastolic blood pressures revealed no significant statistical differences $(p>0.05)$. Therefore, both groups were similar in respect to haemodynamic variables.

The next observations were done just after laryngoscopy and intubation. The mean pulse rates in Group I and II were $99.3 \pm 4.43$ and $86.57 \pm 3.33$ beats per minute respectively. The mean systolic blood pressures in Group I and II were $155.5 \pm 6.89$ and $127.77 \pm 4.58$ respectively. The mean diastolic blood pressures in Group I and II were $93.67 \pm 4.98$ and $79.73 \pm 2.45$ respectively. The pulse rates and blood pressures were increased in both groups. When compared to Group I, Group II had less increase in pulse rates and blood pressures. The differences of pulse rates and blood pressures were highly significant between the groups ( $p<0.0001)$. Similar observations were seen by Batra et al, ${ }^{4}$ Nishikawa et al, ${ }^{5}$ Carbine UA et al, 6 Leslie et al, ${ }^{7}$ Ghingone et al ${ }^{13}$ and Wright et al ${ }^{14}$ that the rise in pulse rates and blood pressures were significantly less in clonidine treated groups.

At 1 minute after laryngoscopy and intubation, the mean pulse rates in Group I and II were $103.4 \pm 4.69$ and $90.6 \pm$ 3.46 beats per minute respectively. Increase in pulse rates were $36.77 \%$ in Group I and $19.37 \%$ in Group II from baseline. The mean systolic blood pressures in Group I and II were $161.3 \pm 9.51$ and $132.4 \pm 5.04 \mathrm{mmHg}$ respectively. Increase in mean systolic blood pressures were $26.31 \%$ in Group I and $4.22 \%$ in Group II from baseline. The mean diastolic blood pressures in Group I and II were $97.33 \pm 4.47$ and $83.77 \pm 3.46 \mathrm{mmHg}$ respectively. Increase in mean diastolic blood pressures were $23.31 \%$ in Group I and 6.35\% in Group II from baseline. Maximum increase in pulse rates and blood pressures was found at 1 minute after laryngoscopy and intubation. Increase in pulse rates and blood pressures were found more in Group I than Group II. The differences of pulse rates and blood pressures were highly significant between the groups ( $p<0.0001)$. It was seen that clonidine prevents rise in pulse rates and blood pressures in Group II.

The heart rates and blood pressures were progressively decreased from 1 minute after laryngoscopy and intubation to 10 minutes after laryngoscopy and intubation. At 10 minutes after laryngoscopy and intubation, heart rates and blood pressures were similar to baseline. The mean pulse rates in Group I and II were $86.7 \pm 3.88$ and $75.3 \pm 3.82$ beats per minute respectively at 5 minutes after laryngoscopy and intubation and $74.33 \pm 6.25$ and $75.33 \pm 2.96$ beats per minute respectively at 10 minutes after laryngoscopy and intubation. The mean systolic blood pressures in Group I and II were $143.63 \pm 6.92$ and $126.2 \pm 4.25 \mathrm{mmHg}$ respectively at 5 minutes after laryngoscopy and intubation and $127.2 \pm 4.46$ and $125.56 \pm 3.82 \mathrm{mmHg}$ respectively at 10 minutes after laryngoscopy and intubation. The mean diastolic blood pressures in Group I and II were $84.57 \pm 2.53$ and $76.33 \pm$ $2.86 \mathrm{mmHg}$ respectively at 5 minutes after laryngoscopy and intubation and $76.23 \pm 4.13$ and $76.03 \pm 3.41 \mathrm{mmHg}$ respectively at 10 minutes after laryngoscopy and intubation. The differences of pulse rates and blood pressures were significant between the groups upto 5 minutes after laryngoscopy and intubation ( $p<0.0001)$. At 10 minutes after laryngoscopy and intubation, pulse rates and blood pressures were returned to baseline in both groups and differences were statistically not significant $(p>0.05)$. The pulse rates and blood pressures returned to the baseline earlier in clonidine treated groups than control group. So, clonidine leads to early normalisation of haemodynamic changes during laryngoscopy and intubation.

There was no noticeable ECG change in all three groups during the study period. Changes in oxygen saturation were not significant in all groups during the study period.

The side effects and complications of clonidine like bradycardia and hypotension were not observed in any patient during the study period.

The observations of the present study clearly demonstrate that clonidine significantly attenuates haemodynamic responses during laryngoscopy and intubation.

\section{CONCLUSION}

From the present study, it can be concluded that laryngoscopy and intubation are invariably associated with rise in pulse rate and blood pressure. Clonidine is beneficial in attenuating haemodynamic responses to laryngoscopy and intubation and leads to early normalisation of haemodynamic changes during laryngoscopy and intubation. So, clonidine is a useful pre-medicant.

\section{ACKNOWLEDGEMENT}

I pay my deepest regard to Prof. (Dr.) H. N. Prasad, Head of the Department, Dr. Ashok Kumar and Dr. Rajesh Verma, Department of Anaesthesiology, Patna Medical College and Hospital, Patna for their help and inspiration during this work. My sincere thanks to my colleagues and all staffs of the department and hospital for their help in this work. Finally, I am grateful to all my patients included in the study for their co-operation during the study.

\section{REFERENCES}

[1] Reid LC, Brace DE. Irritation of the respiratory tract and its reflex effect upon the heart. Surg Gynecol Obstet 1940;70:157-62.

[2] King BD, Harris LC Jr, Greifenstein FE, et al. Reflex circulatory responses to direct laryngoscopy and tracheal intubation performed during general anesthesia. Anesthesiology 1951;12(5):556-66.

[3] Prys-Roberts C, Greene LT, Meloche R, et al. Studies of anaesthesia in relation to hypertension. II. Haemodynamic consequences of induction and endotracheal intubation. Br J Anaesth 1971;43(6):53147.

[4] Batra YK, Indu B, Puri GD. Attenuation of pulse rate and blood pressure response to laryngoscopy and tracheal intubation by clonidine. International Journal of Clinical Pharmacology, Therapeutics and Toxicology 1988;26(7):360-3.

[5] Nishikawa T, Taguchi M, Kimura T, et al. Effects of clonidine premedication upon haemodynamic changes associated with laryngoscopy and intubation. Masui (Japan) 1991;40(7):1083-8.

[6] Carabine UA, Wright PMC, Moore J. Pre-anaesthetic medication with clonidine: a dose-response study. $\mathrm{Br} \mathrm{J}$ Anaesath 1991;67(1):79-83. 
[7] Leslie K, Mooney PH, Silbert BS. Effects of intravenous clonidine: effect of the cardiovascular response to intubation. Anesth Analg 1991;72:S327.

[8] Marinangeli F, Cocco C, Ciccozzi A, et al. Haemodynamic effects of intravenous clonidine on propofol or thiopental induction. Acta Anaesthesiol Scand 2000;44(2):150-6.

[9] Devault M, Griefenstein FE, Harris LC Jr. Circulatory response to endotracheal intubation in light general anaesathesia-the effect of atropine and phentolamine. Anaesthesiology 1960;21:360-2.

[10] Stoelting RK. Blood pressure and their rate changes during short-duration larygoscopy for tracheal intubation: influence of viscous or intravenous lidocaine. Anaesth Analg 1978;57(2):197-9.
[11] Parnass SM, Rothenberg DM, Kerchberger JP, et al. A single bolus dose of esmolol in the prevention of intubation induced tachycardia and hypertension in an ambulatory surgery unit. J Clin Anesth 1990;2(4):232-7.

[12] Zalunardo MP, Zollinger A, Spahn DR, et al. Effect of intravenous and oral clonidine on hemodynamic and plasma-catecholamine response due to endotracheal intubation. J Clin Anesth 1997;9(2):143-7.

[13] Ghingone M, Cavillo 0, Quintin L. Anesthesia and hypertension: the effect of clonidine on perioperative hemodynamics and isoflurane requirements. Anesthesiology 1987:67(1):3-10.

[14] Wright PMC, Carbine UA, McClune S, et al. Preanaesthetic medication with clonidine. Br J Anaesath 1990;65(5):628-32. 